\title{
Somatic mosaicism of the PIK3CA gene identified in a Hungarian girl with macrodactyly and syndactyly
}

\author{
Kornélia Tripolszki ${ }^{a}$, Rachel Knox ${ }^{b}$, Victoria Parker ${ }^{b}$, Robert Semple ${ }^{b}$, Katalin Farkas ${ }^{\text {, }}$, \\ Adrien Sulák ${ }^{a}$, Emese Horváth ${ }^{a}$, Márta Széll ${ }^{\mathrm{a}, \mathrm{c}}$, Nikoletta Nagy ${ }^{\mathrm{a}, \mathrm{c}, \text { * }}$ \\ ${ }^{a}$ Department of Medical Genetics, University of Szeged, Szeged, Hungary \\ ${ }^{\mathrm{b}}$ Metabolic Research Laboratories, Institute of Metabolic Science, Addenbrooke's Hospital Cambridge, Cambridge, UK \\ c MTA-SZTE Dermatological Research Group, University of Szeged, Szeged, Hungary
}

\section{A R T I C L E I N F O}

\section{Article history:}

Received 13 July 2015

Received in revised form

27 January 2016

Accepted 1 February 2016

Available online $\mathrm{xxx}$

\section{Keywords:}

Overgrowth syndromes

Macrodactyly and syndactyly

PIK3CA gene

Somatic mutation

Phenotypic diversity

\begin{abstract}
A B S T R A C T
Isolated macrodactyly (OMIM 155500) belongs to a heterogeneous group of overgrowth syndromes. It is a congenital anomaly resulting in enlargement of all tissues localized to the terminal portions of a limb and caused by somatic mutations in the phosphatidylinositol 3-kinase catalytic alpha (PIK3CA, OMIM 171834) gene. Here we report a Hungarian girl with macrodactyly and syndactyly. Genetic screening at hotspots in the PIK3CA gene identified a mosaic mutation (c.1624G > A, p.Glu542Lys) in the affected tissue, but not in the peripheral blood. To date, this somatic mutation has been reported in eight patients affected by different forms of segmental overgrowth syndromes. Detailed analysis of the Hungarian child and previously reported cases suggests high phenotypic diversity associated with the p.Glu542Lys somatic mutation. The identification of the mutation provides a novel therapeutic modality for the affected patients: those who carry somatic mutations in the PIK3CA gene are potential recipients of a novel "repurposing" approach of rapamycin treatment.
\end{abstract}

(C) 2016 Elsevier Masson SAS. All rights reserved.

\section{Introduction}

Macrodactyly (OMIM 155500) refers to a rare congenital malformation occurring in approximately 1 in 100,000 live births and is characterized by an increase in the size of all the structures of the limbs, including soft tissues, bones, vessels, nerves and skin (Rios et al., 2013). It typically affects the terminal portions of the limb within a "nerve territory" and the individual peripheral nerve is both enlarged and elongated (Rios et al., 2013). Recently macrodactyly has been added to the growing list of overgrowth syndromes caused by somatic mutations of the phosphatidylinositol 3-kinase catalytic alpha (PIK3CA, OMIM 171834) gene (Rios et al., 2013; Kurek et al., 2012; Emrick et al., 2014).

Further somatic overgrowth diseases associated with mosaic PIK3CA mutations include fibroadipose hyperplasia and nonclassifiable conditions characterized by muscular, boney and fatty tissue overgrowth, congenital lipomatous overgrowth, vascular malformations, epidermal nevi and skeletal abnormalities

\footnotetext{
* Corresponding author. Department of Medical Genetics, University of Szeged, 4 Somogyi utca, H-6720, Szeged, Hungary.

E-mail address: nikoletta.nagy@gmail.com (N. Nagy).
}

(CLOVES) syndrome, hemihyperplasia multiple lipomatosis, and the brain overgrowth conditions megalencephaly capillary malformation and megalencephaly-polymicrogyria-hydrocephalus syndrome (MPPH) (Kurek et al., 2012; Lee et al., 2012; Lindhurst et al., 2012; Rivière et al., 2012; Mirzaa et al., 1993-2011; Rasmussen et al., 2014). The phenotypic heterogeneity in these syndromes is attributed to the location of the cells bearing the mutation and to the proportion of the affected cells in the patient's tissues (Cohen et al., 2014).

Here we describe a 4-year-old Hungarian patient with isolated macrodactyly and syndactyly caused by the c.1624G > A, p.Glu542Lys somatic mutation of the PIK3CA gene. We also provide detailed comparison of the clinical symptoms of the Hungarian patient with previously reported cases having the same p.Glu542Lys somatic PIK3CA mutation.

\section{Clinical report}

A 4-year-old Hungarian girl was referred to the Department of Medical Genetics (University of Szeged, Szeged, HUNGARY) with isolated macrodactyly on the third and fourth fingers of the left hand (Fig. 1a). X-ray imaging proved that the disease is 

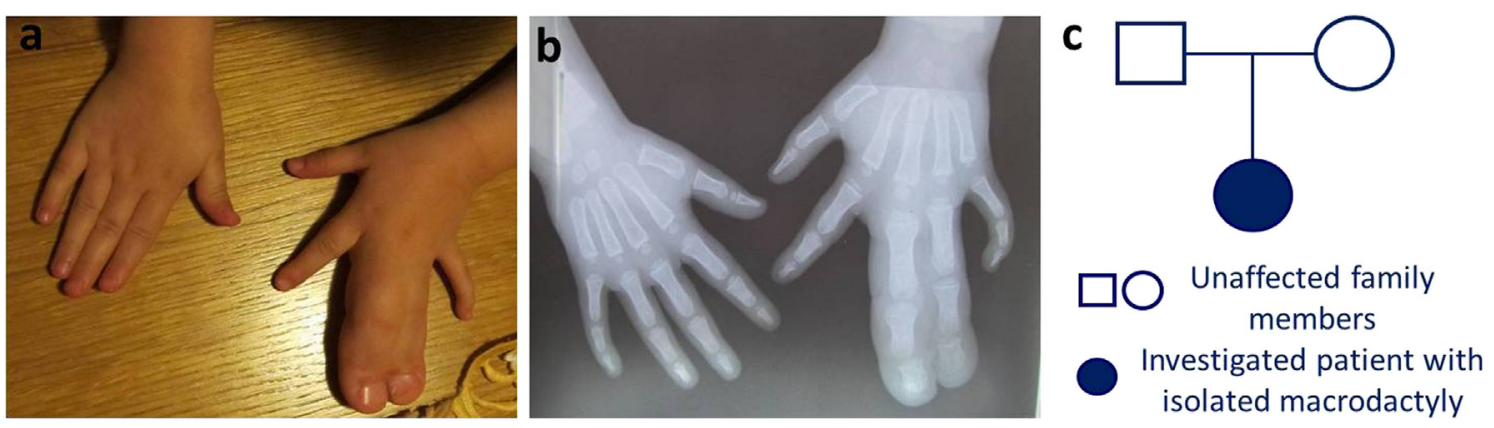

Fig. 1. Macrodactyly and syndactyly in a 4-year-old girl. (a) Clinical features and (b) bone radiographs of the patient. (c) The patient's family is clinically asymptomatic.

characterized not only by the overgrowth of the soft tissues but also by the overgrowth of the bones of the affected fingers (Fig. 1b). In addition to macrodactyly, syndactyly was associated with concrescence of the fingers and was constrained to the soft tissues of the affected fingers and not to the bones (Fig. 1a,b). The macrodactyly and syndactyly of the left hand was present at birth and slowly progressed with the growth of the child. On examination, no vascular abnormality was present. There was no associated abnormality of the internal organs. Other body parts were symmetric and equally developed. The patient's parents were clinically unaffected, and they were not aware of any other family members with either macrodactyly or syndactyly (Fig. 1c).

The performed genetic investigation was approved by the Internal Review Board of the University of Szeged. The study was conducted according to the Principles of the Declaration of Helsinki. After informed consent was obtained from the parents, peripheral blood sample and deep surgical excision of the affected left hand were taken in order to perform genetic analysis. Genomic DNA was isolated with the QIAamp DNA Mini Kit (QIAGEN, Hilden, Germany). Primer sequences were obtained from the UCSC Genome Browser. The coding regions and flanking introns of the PIK3CA gene were amplified and sequenced with a traditional capillary sequencer (ABI Prism 7000). Since traditional sequencing did not identify any putative causative variant of the PIK3CA gene, mutational hotspots were screened using an in-house PCR-based restriction fragment assay which has been previously described (Keppler-Noreuil et al., 2014) (Cambridge, UK). Examining the region surrounding codon 542, a PCR product of 180 base pairs in length was amplified and digested with the $X b a I$ restriction enzyme for $2 \mathrm{~h}$ at $37{ }^{\circ} \mathrm{C}$. The resulting fragments were detected by fluorescent read-out using GeneMapper ${ }^{\circledR}$ software with GeneScan LIZ 500 (Life Technologies Corporation) as the size standard. A mosaic mutation at codon 542 (c.1624G > A, p.Glu542Lys) was identified in the affected tissue with $4 \%$ mutation burden (Fig. 2a). This mutation was not present in the genomic DNA sample isolated from the peripheral blood of the patient (Fig. 2b). This genetic analysis confirmed that the development of macrodactyly and syndactyly of the third and fourth fingers of the left hand are the consequence of the mosaicism of the p.Glu542Lys mutation in the PIK3CA gene.

\section{Discussion}

The case reported in this study presented with macrodactyly and syndactyly of the third and fourth fingers of the left hand. Genetic investigation identified a somatic missense gain-offunction mutation (p.Glu542Lys) of the PIK3CA gene (ClinVar database, http://www.ncbi.nlm.nih.gov/clinvar/accession number: SCV000258982). This mutation affects the helical domain of the p $110 \alpha$ catalytic subunit of the PI3K protein (Samuels et al., 2004). Functional studies have previously shown that this p.Glu542Lys variant caused hyperactivation of AKT, a down-stream target of PI3K in the nerve cells of a patient with macrodactyly (Rios et al., 2013). This particular mutation has been reported in eight patients with different forms of segmental overgrowth (Table 1) (Rios et al., 2013; Kurek et al., 2012; Emrick et al., 2014; Maclellan et al., 2014).

Patients with somatic p.Glu542Lys mutation of the PIK3CA gene show high phenotypic diversity; Kurek et al. (2012), for example, described a female and a male patient affected by CLOVES syndrome. In addition to macrodactyly, both patients developed lipomatous overgrowth of the trunk and the limbs and vascular anomalies including lymphatic, capillary and venous malformations. The affected female patient also had a hypoplastic right kidney (Kurek et al., 2012). A subsequent study reported the prenatal diagnosis of CLOVES syndrome in a 27-week-old fetus carrying the same somatic mutation of the PIK3CA gene. The observed clinical symptoms at birth were asymmetric chest and abdomen, bilateral multicystic malformations and asymmetric growth of the left leg with macrodactyly of the left foot and a sandal gap between the first and second toes (Emrick et al., 2014). Rios et al. (2013) reported two patients with the same somatic mutation; both were affected by macrodactyly. However, one of the patients was also affected by true muscular hemihypertrophy, which was also attributed to the presence of the somatic p.Glu542Lys PIK3CA mutation. A subsequent study has also reported three further patients with facial infiltrating lipomatosis, which was attributed to the presence of the somatic p.Glu542Lys mutation (Maclellan et al., 2014). These patients did not exhibit macrodactyly.

The high phenotypic diversity associated with the somatic p.Glu542Lys mutation might be explained by the different time points, in which the mutational events occurred during embryogenesis. Patients with CLOVES syndrome might have developed the same somatic p.Glu542Lys mutation earlier during the embryogenesis than the ones with regional overgrowth (macrodactyly or facial infiltrating lipomatosis).

Genetic analysis has a huge significance for these patients, as once the genetic cause is determined, pharmacological intervention could be considered as a therapeutic option. In the interim, there are no clinically approved therapies for this condition; however there is a theoretical possibility that small molecule inhibitors of the PI3K-AKT-mTOR signaling pathway could be effective therapies for these patients (Segerström et al., 2011; Iacobas et al., 2011). Rapamycin (sirolimus) indirectly targets PI3K and may also be useful in treating macrodactyly (Segerström et al., 2011; Iacobas et al., 2011). In addition, rapamycin has been reported to be effective in isolated cases of allied conditions and may promote a breakthrough in the treatment of macrodactyly and overgrowth syndromes. However, long-term safety data of this treatment in PIK3CA-related overgrowth is currently lacking and, thus, indicates the need for formal clinical trials to evaluate safety 
a

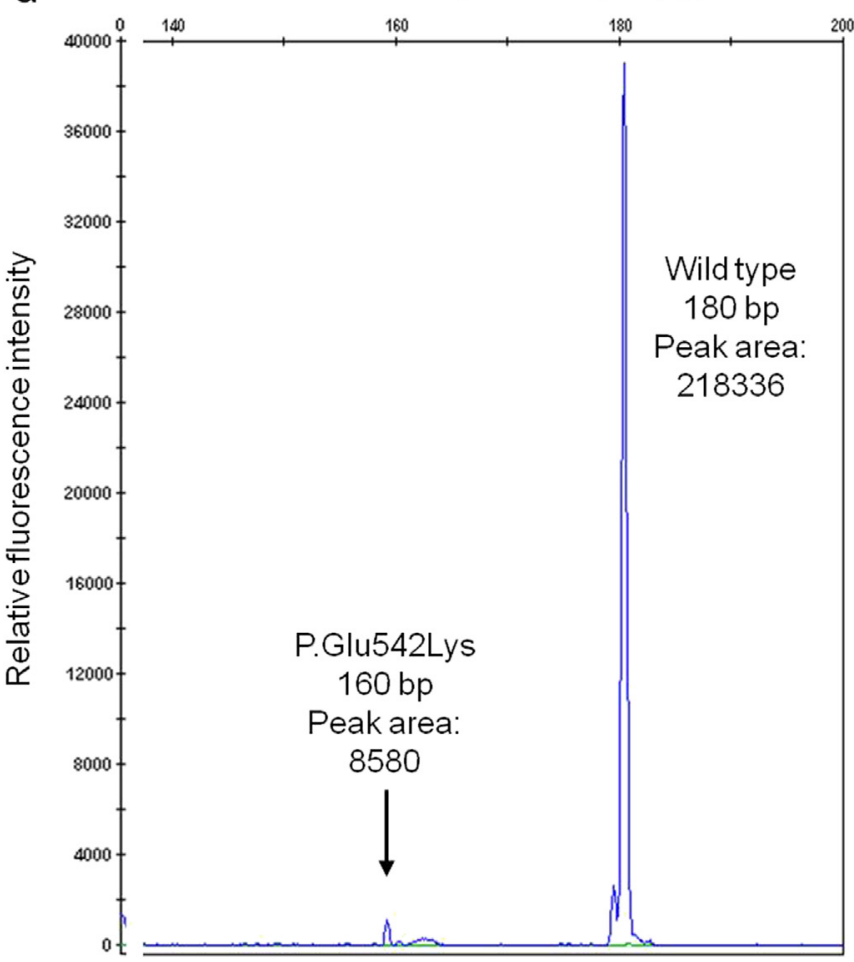

b

Restriction fragment length (bp)

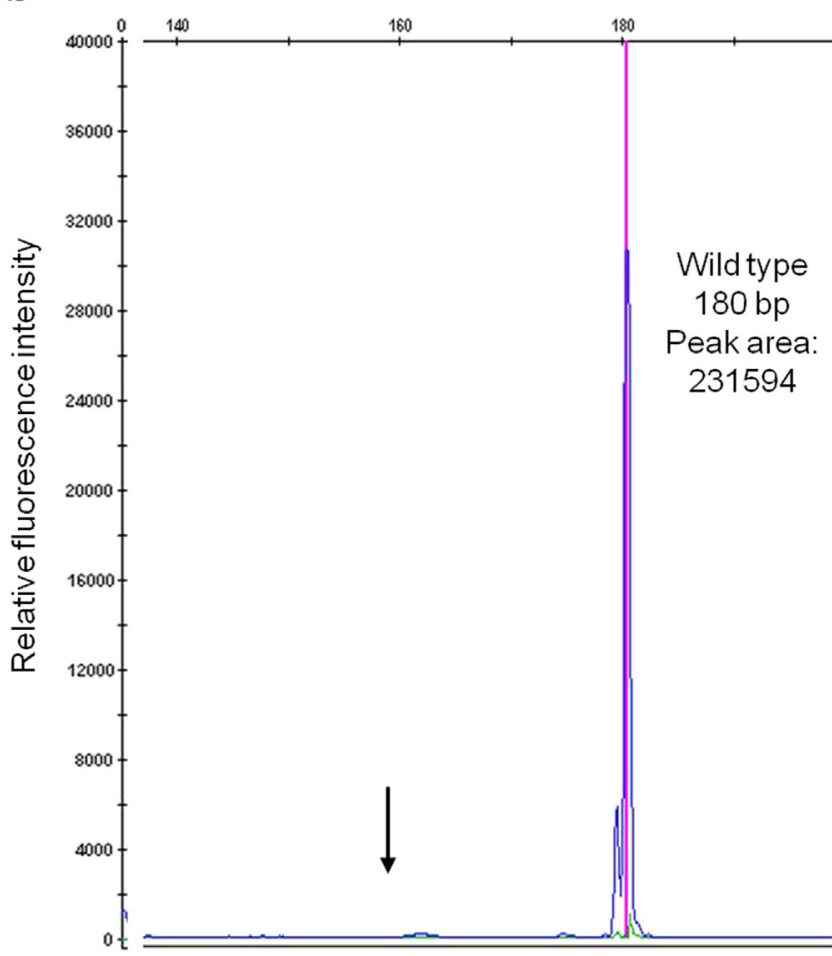

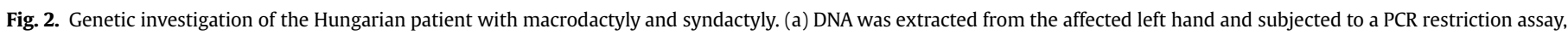

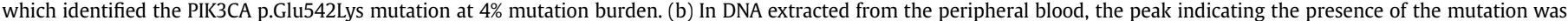
absent in the digested PCR product, indicating the mosaicism of the mutation.

Table 1

Summary of the phenotypic diversity of the patients with somatic p.Glu542Lys PIK3CA mutation.

\begin{tabular}{|c|c|c|c|c|c|c|c|c|c|}
\hline Patients & Index Patient & Patient 2 & Patient 3 & Patient 4 & Patient 5 & Patient 6 & Patient 7 & Patient 8 & Patient 9 \\
\hline Clinical diagnosis & $\begin{array}{l}\text { Macro-dactyly, } \\
\text { Syndactyly }\end{array}$ & $\begin{array}{l}\text { Macro- } \\
\text { dactyly }\end{array}$ & $\begin{array}{l}\text { Macro-dactyly, Muscular } \\
\text { hemi-hypert-rophy }\end{array}$ & $\begin{array}{l}\text { Facial infiltrating } \\
\text { lipo-matosis }\end{array}$ & $\begin{array}{l}\text { Facial infiltrating } \\
\text { lipo-matosis }\end{array}$ & $\begin{array}{l}\text { Facial infiltrating } \\
\text { lipo-matosis }\end{array}$ & $\begin{array}{l}\text { CLOVES } \\
\text { syndrome }\end{array}$ & $\begin{array}{l}\text { CLOVES } \\
\text { syndrome }\end{array}$ & $\begin{array}{l}\text { CLOVES } \\
\text { syndrome }\end{array}$ \\
\hline Publication & This report & $\begin{array}{l}\text { Rios } \\
\text { et al., } \\
2013\end{array}$ & Rios et al., 2013 & $\begin{array}{l}\text { Maclellan et al., } \\
2014\end{array}$ & $\begin{array}{l}\text { Maclellan et al., } \\
2014\end{array}$ & $\begin{array}{l}\text { Maclellan et al., } \\
2014\end{array}$ & $\begin{array}{l}\text { Kurek et al., } \\
2012\end{array}$ & $\begin{array}{l}\text { Kurek } \\
\text { et al., } 2012\end{array}$ & $\begin{array}{l}\text { Emrick } \\
\text { et al., } 2014\end{array}$ \\
\hline $\begin{array}{l}\text { Percentage (\%) of } \\
\text { somatic } \\
\text { mosaicism }\end{array}$ & 4 & NR & NR & 23 & 30 & $16-18$ & 8 & $6-13$ & 38 \\
\hline \multicolumn{10}{|l|}{$\begin{array}{l}\text { Lipomatous } \\
\text { overgrowth }\end{array}$} \\
\hline Face & NR & NR & NR & + & + & + & NR & NR & NR \\
\hline Trunk & NR & NR & NR & NR & NR & NR & + & + & + \\
\hline $\operatorname{Limb}(s)$ & + & + & + & NR & NR & NR & + & + & + \\
\hline \multicolumn{10}{|l|}{ Vascular anomalies } \\
\hline $\begin{array}{l}\text { Lymphatic } \\
\text { malformation }\end{array}$ & NR & NR & NR & NR & NR & NR & + & + & + \\
\hline $\begin{array}{l}\text { Capillary } \\
\text { malformation }\end{array}$ & NR & NR & NR & NR & NR & NR & + & + & + \\
\hline $\begin{array}{l}\text { Venous } \\
\text { malformation }\end{array}$ & NR & NR & NR & NR & NR & NR & + & + & + \\
\hline \multicolumn{10}{|l|}{ Musculoskeletal } \\
\hline Macrodactyly & + & + & + & NR & NR & NR & + & + & + \\
\hline Limb asymmetry & NR & NR & NR & NR & NR & NR & + & + & \\
\hline Scoliosis & NR & NR & NR & NR & NR & NR & + & & \\
\hline $\begin{array}{l}\text { True muscular } \\
\text { hemihypertrophy }\end{array}$ & NR & NR & + & NR & NR & NR & NR & NR & NR \\
\hline Other findings & NR & NR & NR & NR & NR & NR & $\begin{array}{l}\text { Hypo-plastic } \\
\text { right kidney }\end{array}$ & NR & $\begin{array}{l}\text { Epidermal } \\
\text { nevi }\end{array}$ \\
\hline
\end{tabular}

$\mathrm{NR}=$ not reported 
and efficacy. In light of the current situation, detailed genetic investigation and publication of these isolated cases is essential.

\section{Conflicts of interest}

The authors declare that they have no conflict of interest.

\section{Acknowledgments}

This research was supported by the European Union and the State of Hungary, co-financed by the European Social Fund in the framework of TÁMOP-4.2.4.A/2-11/1-2012-0001 "National Excellence Program." Nikoletta Nagy was also supported by the Hungarian Scientific Research Fund (OTKA) PD104782 grant.

\section{References}

Cohen, A.S., Townsend, K.N., Xiang, Q.S., Attariwala, R., Borchers, C., Senger, C., et al., 2014. Somatic mosaicism for the p.His1047Arg mutation in PIK3CA in a girl with mesenteric lipomatosis. Am. J. Med. Genet. 164A, 2360-2364.

Emrick, L.T., Murphy, L., Shamshirsaz, A.A., Ruano, R. Cassady, C.I., Liu, L., et al., 2014 Prenatal diagnosis of CLOVES syndrome confirmed by detection of a mosaic PIK3CA mutation in cultured amniocytes. Am. J. Med. Genet. 164A, 2633-2637. Iacobas, I., Burrows, P.E., Adams, D.M., Sutton, V.R., Hollier, L.H., Chintagumpala, M.M., 2011. Oral rapamycin in the treatment of patients with hamartoma syndromes and PTEN mutation. Pediatr. Blood Cancer 57, 321-323.

Keppler-Noreuil, K.M., Sapp, J.C., Lindhurst, M.J., Parker, V.E., Blumhorst, C., Darling, T., et al., 2014. Clinical delineation and natural history of the PIK3CArelated overgrowth spectrum. Am. J. Med. Genet. 164A, 1713-1733.
Kurek, K.C., Luks, V.L., Ayturk, U.M., Alomari, A.I., Fishman, S.J., Spencer, S.A., et al., 2012. Somatic mosaic activating mutations in PIK3CA cause CLOVES syndrome. Am. J. Hum. Genet. 90, 1108-1115.

Lee, J.H., Huynh, M., Silhavy, J.L., Kim, S., Dixon-Salazar, T., Heiberg, A., et al., 2012. De novo somatic mutations in components of the PI3K-AKT3-mTOR pathway cause hemimegalencephaly. Nat. Genet. 44, 941-945.

Lindhurst, M.J., Parker, V.E., Payne, F., Sapp, J.C., Rudge, S., Harris, J., et al., 2012 Mosaic overgrowth with fibroadipose hyperplasia is caused by somatic activating mutations in PIK3CA. Nat. Genet. 44, 928-933.

Maclellan, R.A., Luks, V.L., Vivero, M.P., Mulliken, J.B., Zurakowski, D., Padwa, B.L. et al., 2014. PIK3CA activating mutations in facial infiltrating lipomatosis. Plast. Reconstr. Surg. 133, 12-19.

Mirzaa, G., Conway, R., Graham, J.M., Dobyns, W.B., 1993-2014. PIK3CA-Related segmental overgrowth. In: Pagon, R.A., Adam, M.P., Ardinger, H.H., et al. (Eds.), GeneReviews $^{\circledR}$ [Internet]. Seattle (WA). University of Washington, Seattle. Available from: www.ncbi.nlm.nih.gov/books/NBK153722/.

Rasmussen, M., Sunde, L., Weigert, K.P., Bogaard, P.W., Lildballe, D.L., 2014 Segmental overgrowth syndrome due to an activating PIK3CA mutation identified in affected muscle tissue by exome sequencing. Am. J. Med. Genet. 164A 1318-1321.

Rios, J.J., Paria, N., Burns, D.K., Israel, B.A., Cornelia, R., Wise, C.A., Ezaki, M., 2013 Somatic gain-of-function mutations in PIK3CA in patients with macrodactyly. Hum. Mol. Genet. 22, 444-451.

Rivière, J.B., Mirzaa, G.M., O'Roak, B.J., Beddaoui, M., Alcantara, D., Conway, R.L. et al., 2012. De novo germline and postzygotic mutations in AKT3, PIK3R2 and PIK3CA cause a spectrum of related megalencephaly syndromes. Nat. Genet. 44 934-940.

Samuels, Y., Wang, Z., Bardelli, A., Silliman, N., Ptak, J., Szabo, S., et al., 2004. High frequency of mutations of the PIK3CA gene in human cancers. Science 304, 554.

Segerström, L., Baryawno, N. Sveinbjörnsson, B., Wickström, M., Elfman, L. Kogner, P., Johnsen, J.I., 2011. Effects of small molecule inhibitors of PI3K/Akt/ mTOR signaling on neuroblastoma growth in vitro and in vivo. Int. J. Cancer 129 , $2958-2965$. 